\title{
Reduction in Substrate Moisture Content Reduce Final Yield of Wheat
}

\author{
Syed Arshad Karim and Imran* \\ Department of Agronomy, The University of Agriculture Peshawar, Pakistan
}

*Corresponding author: Imran, Department of Agronomy, Faculty of Crop Production Sciences, The University of Agriculture

Peshawar, Pakistan

\section{ARTICLE INFO \\ Received: 幽 January 28, 2019 \\ Published: 㓞 February 25, 2019}

Citation: Syed Arshad K, Imran. Reduction in Substrate Moisture Content Reduce Final Yield of Wheat. Biomed J Sci \& Tech Res 15(1)-2019. BJSTR. MS.ID.002656.
ABSTRACT

Wheat (Triticum aestivum L.) is an important crop of Pakistan. In Khyber Pakhtunkwa, wheat is grown on almost $67 \%$ cropped area. Its yield is subjected to availability of rainfall. Delay in rain caused severe yield reduction by early drought stress. Therefore, this experiment was conducted to compare new wheat varieties in relation to reduction in substrate moisture content to find out drought tolerant variety that could withstand the early drought stress. The experiment was conducted in Completely Randomized Design (CRD) in Agronomy Lab, Department of agronomy, the University of Agriculture Peshawar in controlled environment in 2016. Five different wheat varieties seeds were compared in early growth establishment in three repeats with three different moisture level,

a) Low moisture (6\%),

b) Medium moisture (12\%),

c) High moisture (18\%).

The growth substrate silt was used in specially designed glass boxes box of size (23 $\mathrm{x} 16 \mathrm{x} 4 \mathrm{~cm}$ ). All the other environmental conditions were kept similar for each variety and its replicates. Data was recoded on different growth parameters such as germination percentage, root number, plumule length, dry weight of shoot and root, and length of seminal root 1,2 , and 3 . The study confirmed that almost all varieties can withstand at low moisture but significant reduction in different parameters was observed with reduction in moisture content of growth media that could ultimately affect the yield of wheat.

\section{Introduction}

Wheat (Triticumaestivum L.) is cultivated worldwide and Pakistan is the 8thlargest wheat producing country. Wheat is a winter self-pollinated crop of Pakistan and is consumed as major source of staple food in the country. Worldwide, wheat is leading source of vegetable protein in human food, having higher protein content than any the other major cereal crop. In terms of total production in quantity used as food, wheat is currently second to rice in Pakistan cultivation. Grains are used making flour for, flat and steamed breads, biscuits, cookies, and cakes etc. [1] and with fermentation making beer (Palmer) including other alcoholic beverages (Neill). The whole grain is a concentrated source of vitamins, leavened minerals, and protein, while refined grain is mostly starch. China, India and Russia are the world's major producers of wheat. Wheat belongs to the family gramineae and is main crop used as food in all parts of the world. The largest cultivated area of the world is planted with wheat when compared with any other crops in cultivation. It is, therefore, known as a king of cereals. Wheat occupies $46 \%$ cultivated area of the country with an average yield of $2657 \mathrm{~kg}$ ha-1 (MINFA).

Wheat in Pakistan is gown both irrigated and rain fed where in Khyber Pakhtunkhawa, almost 70\% crop is grown as rain fed. Efforts are in progress to breed for high yield, better protein quality, biotic and abiotic stresses resulting in development of many cultivars [2]. Understanding of genetic diversity in a crop species is key to its improvement under changing environments [3]. Early seedling establishment is extremely important in determining the yield of crop in short period of time (Misra). Early seedling vigor is also considered an important component of plant development 
under most of environmental conditions (Khan). Crop varieties having genetic potential for early seedling vigor use available soil water efficiently, resulting in better dry matter accumulation and higher optimum grain yield [4]. Successful varieties of future must possess characters allowing them to produce higher yield under drought, salinity and extreme temperature. Roots are the hidden part, play several essential roles in a plant life cycle. They are important not only for the uptake of nutrients and water but also for environmental stress tolerance.

Therefore, plants have several ways to modify their root system architecture in response to changes in external environment (Osmont). Analyses of genetic factors contributing to root system are still very limited, however, partly because of the difficulty of observing the distribution of roots in field conditions and partly because of complication of the effects of environmental conditions on root system. To overcome these difficulties, researchers have been working on relationship between root characteristics at seedling stage. Seed germination and seedling growth traits are extremely important factors in determining yield (Rauf). Dhandas [5] indicated that seed vigor index and plumule length are most sensitive traits to drought stress. Seedling emergence is one of the most sensitive growth stages that are susceptible to waterdeficit. Therefore, seed germination, seedling vigor and coleoptile's length are fundamentals for successful stand establishment of crop plants, (Manschadi). Keeping in view the importance of wheat varieties and characteristics of early seedling establishment in crop production the present study was aimed to know and compare different varieties with different moisture levels or water stress for early establishment of germination percentage, plumule length and seminal roots growth, and to assess wheat varieties for root mass and growth rate.

Also, to study the effect of different moisture levels on root and shoot elongation. To estimate elongation rates at early seedling stage. And find out a variety that could withstand with less moisture level. Gulnaz (2012) determined the potential of a collection of 100 wheat genotypes for improved varieties in terms of traits like number of spikes per plant, plant height, spike length, peduncle length, extrusion length, and number of spikelets per spike, 1000-grain weight, and grain yield per plant, coleoptile length, root length, shoot length and number of seminal roots. Out of eleven, four PCs were significant exhibiting more than one eigenvalue. The first four PCs had $58.06 \%$ variation. The PC1, PC2, PC3 and PC4 had 21.27, 15.99, 10.73 and 10.07\% variability respectively, among the genotypes for traits under study. Atta [6] conducted experiment to assess the impact of genotypic variation for root traits on WUE and yield. Their results indicated significant variation in all root traits among wheat genotypes in both high and low moisture environments. A significant reduction in the overall expression of these root traits was observed in response to water stress. Maximum root trait values were observed near the surface
(0-15 cm depth) and these decreased with depth with the exception of root diameter in non-water limiting conditions [7-15].

Mean root length density in both environments was greater than $0.5 \mathrm{~cm}^{3}$ which was considered sufficient to extract all the moisture from the soil. Stronger relationships between root and above ground traits were observed when water was not limiting. Under water stress, crop water extraction and adaptation depend on root distribution. The genotypes with superior root characteristics can be combined in crosses with sources of resistance to root diseases, such as crown rot, to improve the adaptation of wheat in north -western NSW. Shah (2011) studied the effect of different moisture regimes on root growth of maize varieties. Four moisture treatments i.e. favorable (100\%), moderate (75\%), low (50\%) and very low $(25 \%)$ were prepared with sand soil mixtures of $8: 1(\mathrm{w} / \mathrm{w})$. Ten varieties of maize comprising three hybrids and seven synthetics were compared for the seminal root length and elongation rates. The results showed that a reduction in root length was common by decreasing substrate moisture from favourable to any level. However, the decrease in root length was moderate to stronger when substrate's moisture contents decreased form below $75 \%$ [16-22].

Different varieties responded differently to the reduction in soil moisture contents showing that potential did exist in genotype for further improvement e.g. identification of marker genes and its transferring to existing commercial varieties to adopt them better in an environment when sowing was accomplished in hot summer months in soils where loss of moisture was relatively high. Reduction in substrate moisture has shown a decrease in root length which might has an almost similar effect on seedling establishment in early development phase and hence can accumulate in yield losses at maturity. Abdoli and Saeidi (2012) studied the effect of terminal water deficiency stress on yield and its components, seed germination and vigor of nine wheat cultivars (Bahar, Parsi, Pishtaz, Pishgam, Chamran, Zarin, Sivand, Marvdasht and DN-11). The results showed that post anthesis water deficiency significantly decreased grain yield, biomass, 1000 grain weight and grain number spike-1 in cultivars. Under post-anthesis water deficiency, cultivars in terms of all under-study traits had significant differences. In the second experiment, influence of water deficiency stress in farm on germination percentage and seedling growth parameters have been measured [23-30].

Based on laboratory results, water deficiency stress in farm caused reduction in all germination characteristics, except plumule to radicle ratio and mean germination time. According to farm and laboratory results, it can be said that Sivand cultivar with the highest yield and grain weight had the best germination characteristics and less affected by water deficiency stress. Also, Pishgam and DN11 were the next cultivars based on germination characteristics. Sharifi (2014) evaluated the effects of salt stress on the seed germination and seedling growth of four wheat varieties (Soasel, 
Shahriyar, Zarin, and Cascogen) and four different concentrations of sodium chloride (2 g/lit $(0.05 \mathrm{M}), 5 \mathrm{~g} /$ lit $(0.12 \mathrm{M}), 8 \mathrm{~g} / \mathrm{lit}(0.2$ M), $11 \mathrm{~g} / \mathrm{lit}(0.28 \mathrm{M})$ and control. The results of laboratory study showed that the influence of various treatments on germination percentage was significant. $2 \mathrm{~g} /$ lit $(0.05 \mathrm{M})$ showed the highest positive effect on germination percentage for Zarin variety. Also, the shortest ratio of radicle/plumule was associated with Zarin type. Baloch et al. [31] Screened out sixteen spring wheat cultivars were screened under osmotic stress with three treatments i.e. control-no PEG (polyethylene glycol), 15 percent and 25 percent PEG-6000 solution.

The analysis of variance indicated significant differences among treatments for all seedling traits except seed germination percentage. Varieties also differed significantly in germination percentage, coleoptile length, shoot root length, shoot weight, root/shoot ratio and seed vigor index. However, shoot and root weights were non-significant. Significant interactions revealed that cultivars responded variably to osmotic stress treatments; hence provided better opportunity to select drought tolerant cultivars at seedling growth stages. The relative decrease over averages due to osmotic stress was 0.8 percent in seed germination, 53 percent in coleoptile length 62.9 percent in shoot length, 74.4 percent in root length, 50.6 percent in shoot weight, 45.1 percent in root weight, 30.2 percent in root/shoot ratio and 68.5 percent in seed vigor index. However, relative decrease of individual variety for various seedling traits could be more meaningful which indicated that cultivar TD-1 showed no reduction in coleoptile length, while minimum decline was noted in Anmol. For shoot length, cultivar Sarsabz expressed minimum reduction followed by Anmol. However, cultivars Anmol, Moomal, Inqalab-91, and Pavan gave almost equally lower reductions for root length suggesting their higher stress tolerance [31-40].

In other words, cultivars Anmol, Moomal, Inqalab-91, Sarsabz, TD-1, ZA-77 and Pavan had relatively longer coleoptiles, shoots and roots, and were regarded as drought tolerant. Correlation coefficients among seedlings traits were significant and positive for all traits except germination percentage which had no significant correlation with any of other trait. The results indicated that increase in one trait may cause simultaneous increase in other traits; hence selection for any of these seedling attributes will lead to develop drought tolerant wheat cultivars. Narayan (2014) determined whether root traits are related to shoot traits (plant height, tiller number per plant, shoot dry weight, and coleoptile length), regions of origin, and market classes. Rooting depth, root dry weight, root: shoot ratio, and shoot traits were determined for 297 genotypes of the germplasm, Cultivated Wheat Collection (CWC). The remaining root traits such as total root length and surface area were measured for a subset of 30 genotypes selected based on rooting depth. Significant genetic variability was observed for root traits among spring wheat genotypes in CWC germplasm or its subset. Genotypes Sonora and Currawa were ranked high, and genotype Vandal was ranked low for most root traits. A positive relationship was found between roots and shoot dry weights within the CWC germplasm and between total root surface area and tiller number; total root surface area and shoot dry weight; and total root length and coleoptile length within the subset [41-50].

No correlations were found between plant height and most root traits within the CWC germplasm or its subset. Region of origin had significant impact on rooting depth in the CWC germplasm. Wheat genotypes collected from Australia, Mediterranean, and west Asia had greater rooting depth than those from south Asia, Latin America, Mexico, and Canada. Soft wheat had greater rooting depth than hard wheat in the CWC germplasm. Emam and Bijanzadeh [51] investigated root anatomy and hydraulic conductivity of wheat cultivars, including Shiraz, Bahar, Pishtaz, Sistan, and Yavaros. Seminal roots had four to five cortical cell layers, and typically one large central metaxylem and $5 \pm 1$ (in Bahar) to $7 \pm 1$ (in Yavaros) smaller and circularly arranged peripheral metaxylem vessels. Stellar cells were less lignified in adventitious roots, as compared with seminal roots, and mature xylem vessels of seminal roots of Shiraz and Yavaros cultivars had more lignified walls compared to the other cultivars of the 18-day old plants. Lateral roots of Shiraz cultivar showed the most lignified walls compared to the other cultivars. The highest root hydraulic conductivity in seminal roots was observed in Bahar with the lowest surface area and lignified cell walls. Type of cultivar had also a noticeable effect on flow rate of seminal roots and varied from 2.81 in Shiraz to $3.76 \times 10-10 \mathrm{~m}$ $\mathrm{s}-1$ in Bahar cultivar. With respect to flow rate and osmotic driving force of seminal and adventitious roots, Bahar and Sistan cultivars had the highest hydraulic conductivity [52-63].

\section{Conclusion}

A better developed root system is an important character for drought avoidance, and this can enable plants to produce more dry matter under the conditions of insufficient soil moisture because plants can uptake much water from soil.

\section{References}

1. Cauvain S, CP Cauvain (2003) Bread making. CRC press pp540.

2. Al Maskri AH, M Sajjad, SH Khan (2012) Association mapping: a step forward to discovering new alleles for crop improvement. Int J Agric Biol 14: $153-160$.

3. Gulnaz S, SH Khan, M Shahzad, W Nasim, M Sajjad (2012) Genetic evaluation of spring wheat (Triticum aestivum L.) germplasm for yield and seedling vigor traits. J Agric Soc Sci 8: 123-128.

4. Awan SI, MFA Malik, M Siddique (2005) Study on seedling traits for drought tolerance in wheat under moisture stress conditions. SAARC J Agric 3: 247-254

5. Dhandas SS, GS Sethi, RK Behl (2004) Indices of drought tolerance in wheat genotypes at early stages of plant growth. J Agron And Crop Sci 190(1): 6-12.

6. Atta M, T Mahmood, RM Trethowan (2013) Relationship between root morphology and grain yield of wheat in north Western Australia. Aus J Crop Sci 7(13): 2108-2115. 
7. Abdoli M, M Saeidi (2012) Effects of water deficiency stress during seed growth on yield and its components, germination and seedling growth parameters of some wheat cultivars. Int J Agric Crop Sci 4(15): 110-118.

8. Abdoli M, Saeidi M (2012) Effects of water deficiency stress during seed growth on yield and its components, germination and seedling growth parameters of some wheat cultivars. Inter J Agric Crop Sci 4(15): 11101118.

9. Araus JL, GA Slafer, MP Reynold, C Royo (2002) Plant Breeding and Drought In C3 Cereals: What Should We Breed For? Annuals of Bot S89: 925-940.

10. Bouaziz A, Hicks DR, (1990) Consumption of wheat seed reserves during germination and early growth as affected by soil water potential. Plant and soil 128(2):161-165.

11. Coleman RK, GS Gill, GJ Rebetzke (2001) Identification of quantitative trait loci (QTL) for traits conferring weed competitiveness in wheat (Triticumaestivum L.). Aus J Agric Res 52(12): 1235-1246.

12. Fischer RA (1979) Growth and yield limitation to dry land wheat yield in Australia; a physiological framework. J Aus Inst Agric Sci 45: 83-94.

13. Imran, Amanullah, A Bari, R Ali (2018) Peach sources, phosphorous and beneficial microbes enhance productivity of soybean. Soy Res 16(2): 3948.

14. Imran (2018) Climate Change Is Threat toward Agronomy (Base of Food, Fiber System), and Food Security. Food Nutr J: FDNJ-160.

15. Imran (2018) Physiological and Morphological Traits of Agronomic Crops Influenced By Climate Change. Mod Concep Dev Agrono 1(5): MCDA.000524.

16. Imran (2018) Ecological Environmental Variability Influence Growth and Yield Potential of Rice under Northern Climatic Scenario. Russian Agricultural Sciences 44(1): 18-24.

17. Imran (2018) Phosphorous fertilization influenced weeds attributes and phenological characteristics Of mungbean cultivars (vigna radiata 1.) Russian Agricultural Sciences 44(3): 229-234.

18. Imran, Amanullah (2018) Global impact of climate change on water, soil resources and threat towards food security: evidence from Pakistan. Adv Plants Agric Res 8(5): 350-355.

19. Imran (2018) Physiological and Morphological Traits of Agronomic Crops Influenced By Climate Change. Mod Concep Dev Agrono 1(4): MCDA.000524.

20. Imran (2018) Organic Matter Amendments Improve Soil Health, Productivity and Profitability of Maize and Soybean. Ann Rev Resear 1(3): 555564.

21. Imran and Khan AA (2017) Canola Yield and Quality Enhanced with Sulphur Fertilization Russ. Agricult Sci 43(2): 113-119.

22. Imran, Nasar Jamal, Ashfaq Alam, Asad Ali Khan (2017) Grain Yield, Yield Attributes Of Wheat And Soil Physio-Chemical Charicteristics Influenced By Biochar, Compost And Inorganic Fertilizer Application. Agri Res \& Tech: Open Access J 10(4): 555795.

23. Imran, Abdul Bari, Roshan Ali, Naeem Ahmad, Zulfiqar Ahmad, et al (2017) Traditional Rice Farming Accelerate $\mathrm{CH}_{4} \& \mathrm{~N}_{2} \mathrm{O}$ Emissions Functioning as A Stronger Contributors of Climate Change. Int J Environ Sci Nat Res 9(3): 555765

24. Imran (2017) Climate Change Is a Real Fact confronting to Agricultural Productivity. Int J Environ Sci Nat Res 3(3): 555613.

25. Imran, AA Khan, I Ullah, H zada, F Ahmad, et al. (2015) Yield and yield attributes of rapeseed cultivars as influence by sulfur level under swat valley conditions. J Pure \& Applied biology 4(3): 296-301.

26. Iqbal A, Amanullah, Ali A, Iqbal M, Ikramullah, et al. (2017) Integrated use of phosphorus and organic matter improve fodder yield of moth bean (Vigna aconitifolia (Jacq.) under irrigated and dryland conditions of Pakistan. Journal of AgriSearch 4(1): 10-15
27. Imran, Shahida Naveed, Asad Ali Khan, Inayat Khattak (2015) Impact of Phosphorus Levels And Seed Rates On Growth And Yield Of Late Sown Maize On High Elevation In Swat, Pakistan. Pakistan J Agric Res 28(4A): 406-413.

28. Babar Iqbal, Mohammad Tariq Jan, Zar Muhammad, Asad Ali Khan, Shazma Anwar, et al. (2016) Phenological traits of Maize influenced by integrated management of compost and fertilizer Nitrogen. J Pure \& Applied biology 5(1): 58-63,

29. Ulfat Samreen, Muhammad Ibrar, Lalbadshah, Shahida Naveed, Imran, et al. (2016) Ethnobotanical study of subtropical hills of Darazinda, Takhte-Suleman range F.R D.I. Khan, Pakistan. Pure and Applied Biology 5(1): 149-164.

30. Shazma Anwar, Israeel, Babar Iqbal, Asad Ali Khan, Imran, et al. (2016) Nitrogen and phosphorus fertilization of improved varieties for enhancing phenological traits of wheat. Pure and Applied Biology 5(3): 511-519.

31. Baloch MJ, J Dunwell, AA Khakwani, M Dennet, WA Jatoi, et al. (2012) Assessment of wheat cultivars for drought tolerance via osmotic stress imposed early seedling growth stages. J Agric Res 50(3): 299-310.

32. Amir Zaman Khan, Imran, Asim Muhammad, Aiman Khalil, Hasina Gul, et al. (2016) Impact of fertilizer priming on seed germination behavior and vigor of maize. Pure and Applied Biology 5(4): 744-751.

33. Imran AA, Khan, Inamullah, Luqman (2015) Weeding stages and their effect on yield and yield components of rice in upper Swat, Pakistan. Pak J Weed Sci Res 21(4): 555-563.

34. Imran AA Khan, IU Khan, S Naveed (2016) Weeds density and late sown maize productivity influenced by compost application and seed rates under temperate environment. Pak J Weed Sci Res 22(1): 169-181.

35. Babar Iqbal, Bashir Ahmad, Inam Ullah, Imran, Asad Ali Khan, et al. (2016) Effect of phosphorus, sulphur and different irrigation levels on phenological traits of Triticale. Pure and Applied Biology 5(2): 303-310.

36. Imran, Zada H, Naveed S, Khattak I, Ahmad S (2016) Variable Rates of Phosphorous Application Influenced Phenological Traits of Green Gram (Vignaradiata L.) J Agri Res 1(3).

37. Shahida Naveed, Muhammad Ibrar, Inayat Khattak, Imtiaz Khan, Imran, et al. (2016) Anthelmintic, Antilice, Insecticidal, Cytotoxic and Phytotoxic Potential of Ethanolic Extracts of Two Wild Medicinal Plants Iphiona Grantioides And Plucheaarguta. J Woulfenia (23) 11: 13-25

38. Imran, Asad Ali Khan, Inamullah Inam, Fayaz Ahmad (2016) Yield and yield attributes of Mungbean (Vigna radiata L.) cultivars as affected by phosphorous levels under different tillage systems. Cogent Food \& Agriculture 2(1): 1151982

39. Imran, I Khattak, I Hussain, A Rehman, S Anwar, et al. (2015) Growth and Yield of Maize Hybrids as effected by different Sowing Dates in Swat Pakistan. J Pure \& Applied biology 4(4).

40. Imran, I Hussain, I khattak, A Rehman, F Ahmad, et al. (2015) Roots nodulation, yield and yield contributing parameters of mungbean cultivars as influenced by different phosphorous level in swat-Pakistan. J. Pure \& Applied biology 4(4): 557-567.

41. Khan MN, Khan I uallah, S Shah, I R Arshad, IMA Zeb, et al. (2015) Effect of potash application on growth, yield and yield components of spring maize hybrids. Pure and Applied Biology 4(2): 195-203.

42. Baber Iqbal, MT Jan, Imran, Zar M, AA Khan, et al. (2015) Growth and phenology of maize as affected by integrated management of compost and fertilizers Nitrogen. J Pure \& Applied biology 4(4).

43. Shamsuddin Baqa, Amir Zaman Khan, Inamullah, Imran, Asad Ali Khan, et al. (2015) Influence of Farm Yard Manure and Phosphorus Application on Yield and Yield Components of Wheat. J Pure \& Applied biology 4(4).

44. Babar Iqbal, Muhammad Tariq Jan, Inamullah, Imran, Asad Ali Khan, et al. (2015) Integrated Management of Compost Type and Fertilizer-N in Maize. J Pure \& Applied biology 4(4): 453-457. 
45. Muhammad Islam, Shazma Anwar, Saqib Bashir, Wajid Ali Khattak, Imran, et al. (2015) Growth and Yield Components of Wheat Varieties as Affected by Dual Purpose Practices. J Pure \& Applied biology. 4(4): 491-496.

46. Imran, Muhammad Uzair, Fazal Maula, Marco Vacirca, Salvatore Farfaglia, et al. (2015) Introduction and promotion of off-season vegetables production under natural environment in hilly area of upper swatPakistan. J Bio, Agric and H care 5(11).

47. Imran, Asad Ali Khan (2015) Effect of transplanting dates on yield and yield components of various rice genotypes in hilly area cold climatic region of khyber pakhtunlhwa-Pakistan. J Bio, agric and Health Care $5(7)$.

48. Imran, Asad Ali Khan, Irfanullah, Fayaz Ahmad (2014) Production potential of rapeseed (brassica napus l.) As influenced by different nitrogen levels and decapitation stress under the rainfed agro-climatic condition of swat Pakistan. J Glob Innov Agric Soc.

49. Imran Asad Ali Khan Fayaz Ahmad (2015) Phenology of Various Rice Genotypes as Affected by Different Transplanting Dates under Cold Climatic Region of Khyber Pakhtunkhwa-Pakistan. J Environ and E Science 5(3).

50. Imran (2015) Effect of Germination on Proximate Composition of Two Maize Cultivars. J Bio, Agric and Health care 5(3).

51. Emam Y, E Bijanzadeh (2012) Water uptake and hydraulic conductivity of seminal and adventitious roots of five wheat cultivars at early growth stage. J Agr Sci Tech 14: 1605-1616.

52. Asad Ali Khan, Imran Fawad Ali Shah Inamullah, Laiq Zada Muhammad Naeem Muhammad Nouman Khan (2015) Phenological Traits of Rice as Influenced by Seedling Age and Number of Seedling per Hill under Temperate Region. J Bio, Agric and Health care 5(3).

53. Imran, Asad Ali Khan, Kashif Akhtar, Sajjad Zaheer, Shah Faisal, et al. (2015) Rice Seedling Characteristics of Various Genotypes Influenced by Different Sowing Dates in Swat-Pakistan. J Environ and E. Science 5(1).

\section{ISSN: 2574-1241}

\section{DOI: 10.26717/BJSTR.2019.15.002656}

Imran. Biomed J Sci \& Tech Res

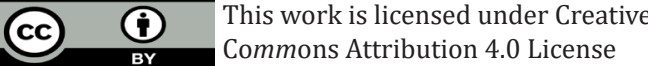

Submission Link: https://biomedres.us/submit-manuscript.php
54. Imran (2015) Influence of Nitrogen Levels and Decapitation Stress on Biological Potential of Rapeseed (Brassica Napus L) under Water Difficit Condition of Swat-Pakistan. J N Sci 5(1).

55. Imran Asad Ali Khan, Fayaz Ahmad and Irfanullah (2015) Nitrogen Levels, Tillage Practices And Irrigation Timing Influenced Yeild, Yeild Components And Oil Contents Of Canola. Civil and Environ Res 7(3).

56. Imran, Asad Ali Khan (2015) Phenological Charateristics of Brassica Napus L. as Influenced by Biochar Application and Shoot Cutting Duration (Days). Civi and Environ Res 7(3).

57. Imran, Asad Ali Khan, Fayaz Ahmad, Irfanullah (2015) Influence of Hydrated Calcium Sulphate (CaSO4.2H2O) and Nitrogen Levels on Water Infiltration Rate and Maize Varieties Productivity in Rainfed Area of Swat, Pakistan. Chem and Envrn Res 7(3).

58. Imran, Asad Ali Khan (2015) Grain Yield and Phenology of Maize Cultivars Influenced by Various Phosphorus Sources. Food Sci and Quality Management 37.

59. Imran, Asad Ali Khan (2015) Biochar Application and Shoot Cutting Duration (Days) Influenced Growth, Yield and Yield Contributing Parameters of Brassica Napus L. J Bio, Agric and Health care 5(5).

60. Imran, Asad Ali Khan (2015) Influence of Compost Application and Seed Rates on Production Potential of Late Sown Maize on High Elevation in Swat -Pakistan. J Environ and E Science.

61. Imran, Fazal Maula, Muhammad Uzair and Hayat Zada (2015) Farmers Income Enhancement through Off-Season Vegetables Production under Natural Environment in Swat-Pakistan. J Environ and E. Science 5(5).

62. Imran, Asad Ali Khan, Hayat Zada, Fayaz Ahmad, Irfanullah (2015) Graine Yield and Yield Components of Wheat Cultivar "Siran 2010" As Affected By Phosphorous Levels under Rain fed Condition. J N Sci Res $5(5)$.

63. Imran (2015) Training case study on capacity development of Parent Teachers councils (PTC) in Khyber Pakhtunkhwa. Journal of Education and Practice. 6(19) 121-124.

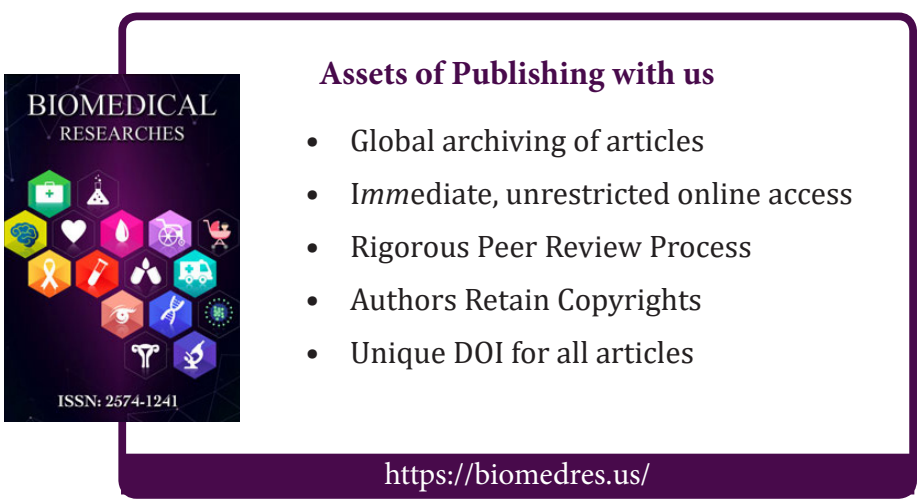

